\title{
CONGRESSIONAL CAMPAIGN EFFECTS ON CANDIDATE RECOGNITION AND EVALUATION
}

\author{
Edie N. Goldenberg and Michael W. Traugott
}

\begin{abstract}
To date, most congressional scholars have relied upon a standard model of American electoral behavior developed in the presidential setting. This research extends our knowledge of Congressmen's incumbency advantages and their sources. Candidate preference is viewed as a function of the relative recognition and evaluation of incumbents and their challengers, as well as of Democrats and Republicans. In the recognition model, contact with voters and media effects are quite important, but there is no direct role for party identification. Evaluation is a function of personal contact and party identification, and media variables are insignificant. Relative recognition, relative evaluation, and party identification are three important predictors of candidate preference, and incumbency itself adds little beyond what is contained in incumbent recognition and evaluation advantages.
\end{abstract}

Until recently, the standard model of American electoral behavior developed in the presidential setting (Campbell, et al., 1960) has been straightforwardly applied to the congressional case by most scholars. The terminology has changed somewhat, but the three basic elements remain: candidates, issues, and party. One candidate characteristic, incumbency, has dwarfed all others in its power to predict the vote, especially for contests for seats in the U.S. House of Representatives. The advantages of incumbency, including better campaign financing, greater name recognition, and more positive voter evaluations, are now accepted as critical factors affecting vote decisions (Jacobson 1980;

An earlier version of this paper was presented at the 1980 annual meeting of the Western Political Science Association, San Francisco, March 1980.

Edie N. Goldenberg and Michael Traugott, Center for Political Studies, The University of Michigan. 
Mann and Wolfinger, 1979; Abramowitz, 1980; Parker, 1980). Our understanding of the sources of these advantages is not yet well developed, and this paper is directed toward an extension of our knowledge of this process.

The analytical emphasis in recent studies of voting in congressional races has shifted from characteristics of individual voters to attributes of the candidates and the context within which they operate. Although this shift in perspective has increased our understanding of voting in congressional races, it is not without its shortcomings. First, it tends to underemphasize, or even neglect, individual voter characteristics as factors influencing vote choice. Although studies routinely include party identification as an independent variable, very few attend to other individual characteristics such as media exposure or education as factors that influence levels of political information and voter response (Converse, 1966; Dreyer, 1971; Robinson, 1974).

Second, no one has yet offered an adequate explanation of the way in which the advantages of incumbency translate into relative electoral success. Although the advantages themselves are abundantly clear in the measures that are commonly used, their linkages to individuals' decisions to participate and to prefer one candidate over another are not. Candidates spend money in different ways, some rather creatively; and some candidates are better able to capitalize on the advantages of their incumbency than others (Goldenberg and Traugott, 1979; Mann, 1978).

This paper represents an initial attempt at dealing with both of these shortcomings. It focuses on several broad types of campaign factorsmedia coverage, candidate mailings, and various forms of personal contact-and their effects on the vote. Moreover, it does so by taking into account variations in the characteristics of individual voters.

\section{DESCRIPTION OF THE MODEL}

Three different operationalizations of the vote have been considered in past studies of voting in congressional elections. The first is turnout, or the decision to participate. The second is the direction of the vote, often referred to as candidate preference. Though almost always defined traditionally in partisan terms, it is now as likely to be operationalized as vote for the incumbent or for the challenger. Finally, as the strength of the relationship between party identification and candidate preference has declined in recent years, defection from self-described identification has become a concept of increasing analytical interest and importance. The measure of vote reported on here is 


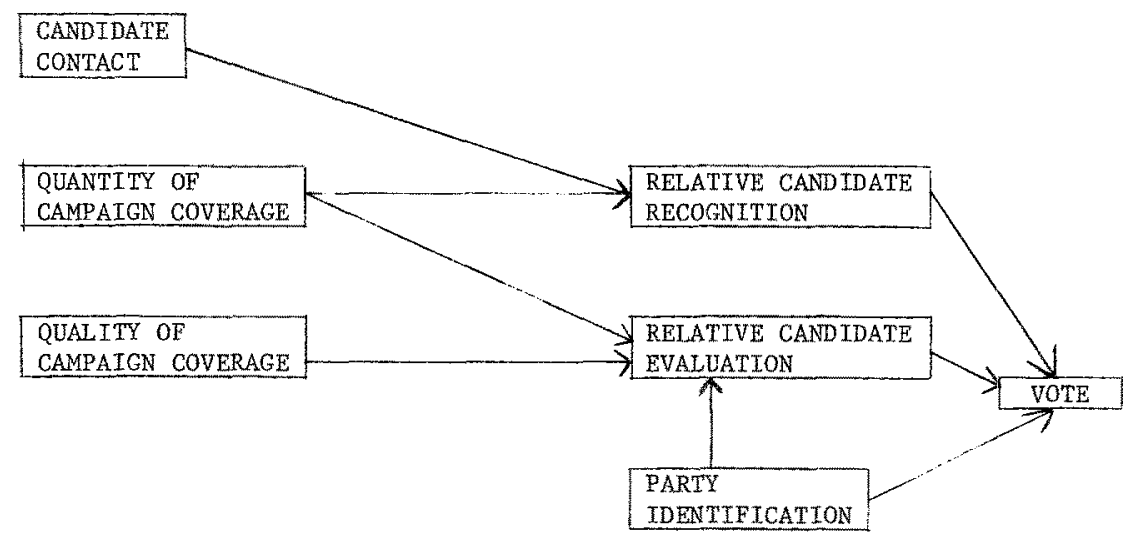

FIGURE 1. A General Model of Voting Behavior in Congressional Elections.

candidate preference. In Figure 1 it is presented as a function of recognition advantage, evaluation advantage, and party identification. The emphasis in the analysis that follows is upon the factors which affect relative candidate recognition-contact with or by the candidates and the quantity of campaign coverage in the media-as well as factors which affect relative candidate evaluation-the quality of campaign coverage in the media and the party identification of the individual voter.

It is well understood that incumbents are better known and more positively evaluated than their challengers. This has been attributed to the incumbents' ability to control their press (Mann and Wolfinger, 1979) or, more generally, to the information constituents receive about them from other sources as well (Mayhew, 1974; Abramowitz, 1975). These findings suggest that the sources of recognition and evaluation advantage may lie in such campaign activities as mass media coverage, personal forms of contact and campaign mailings.

However, the information disseminated in the campaign does not act on an undifferentiated electorate. The likelihood that a given voter may defect from partisan preference is a function not only of the strength of the short-term forces away from the candidate representing the voter's party, but also of the mass of stored information about politics that the voter holds. According to Converse, there are two groups of voters who would be expected to demonstrate stability in their partisan preferences. First there are those people with little stored information about politics who are most vulnerable to short-term appeals, but who are also the least likely to be exposed to those appeals through the media. Because they are not exposed, their partisan voting is relatively stable. 
Also stable are those voters with a great deal of political information. They are exposed to considerable information through the media, but they are relatively invulnerable to its influence. Converse suggests that the relationship between party identification and party vote is a curvilinear one, controlling on levels of media exposure, with those both least and most exposed to the media demonstrating the most stable partisan preferences. Those individuals in the middle show the greatest tendency to defect.

Converse's findings were derived from presidential elections during the 1950s. Dreyer (1971) argues that data for more recent presidential elections do not exhibit this curvilinearity. Rather, they show a positive and monotonic relationship between stability and exposure to a variety of political communications. From this, Dreyer concludes that by now, media coverage of presidential candidates in the campaign has effectively penetrated all segments of the electorate, and consequently, even the least exposed are still exposed enough to produce relatively unstable partisan voting behavior.

However, there is good reason to believe that congressional elections are quite different in this regard. The media penetration of congressional campaigns is nowhere near as complete as that in races for the presidency (Converse, 1966, pp. 142-3, 149). The correspondence between television media markets and congressional district boundaries is poor, so advertising through this medium is limited. The amount of coverage of congressional candidates and campaigns in newspapers is also quite low, as will be discussed in greater detail below. Consequently, one might expect to observe a curvilinear relationship in the congressional context, demonstrating the combined effects of new political information and the individual's mass of stored political information on voter preference.

Data are presented in Table 1 which are similar to those used by Converse and Dreyer, showing the relationship between party identification and party vote for presidential and congressional voting from 1960 to the present by exposure to various political communications media. ${ }^{1}$ The curvilinear relationship does seem to exist for congressional voting. It appears that the low-exposure individuals do not receive enough communication for their vulnerability to short-term forces to be activated, and they are relatively stable in their partisan voting behavior. Those exposed to two or three different media are slightly less stable; those exposed to all four types of media are somewhat more stable. Although it is true that the political communications measure is based on several questions about the respondent's use of various media to obtain general campaign information rather than 
TABLE 1. Tau-Beta Correlations Between Party Identification and Party Vote in Presidential and Congressional Elections, by Exposure to Political Communication, 1960-1978.

\begin{tabular}{|c|c|c|c|c|c|}
\hline \multirow[b]{2}{*}{ Election } & \multicolumn{5}{|c|}{ Exposure to Political Communication } \\
\hline & Lowest & & & & Highest \\
\hline 1960 Presidential & .24 & .56 & .75 & .76 & .80 \\
\hline 1960 Congressional & 1.00 & .58 & .84 & .72 & .87 \\
\hline 1964 Presidential & .21 & .58 & .59 & .62 & .70 \\
\hline 1964 Congressional & .77 & .63 & .69 & .69 & .61 \\
\hline 1968 Presidential & .34 & .48 & .56 & .54 & .75 \\
\hline 1968 Congressional & .84 & .64 & .65 & .60 & .67 \\
\hline 1972 Presidential & .75 & .41 & .48 & .60 & .72 \\
\hline 1972 Congressional & .58 & .50 & .67 & .58 & .71 \\
\hline 1976 Presidential & .47 & .68 & .63 & .63 & .79 \\
\hline 1976 Congressional & .79 & .52 & .63 & .64 & .58 \\
\hline 1978 Congressional & .63 & .65 & .52 & .53 & .52 \\
\hline
\end{tabular}

The correlations for presidential voting from 1960 to 1968 are taken directly from Table 3 of Edward C. Dreyer, "Media Use and Electoral Choices: Some Political Consequences of Information Exposure," Public Opinion Quarterly 35 (Fall 1971), p. 552. The correlations for presidential voting for 1972 and 1976 and for congressional voting from 1960 to 1978 were computed from equivalent CPS National Election Studies in those years.

about the congressional campaign specifically, this measure is highly related to a measure of newspaper readership about the congressional race. $^{2}$

The data suggest the need to account for individuals' mass of stored political information in the analysis of media effects on candidate evaluation. We attempt to do this by examining models separately by level of education. We expect less-well-educated people to have a smaller mass of political information and therefore to be more susceptible to whatever information they do receive. In addition, we expect education level to affect candidate recognition as well. Better educated people should be more able to translate information received into information stored-recognition of the candidate. We separate personal contact from mailings and mass media in order to compare the effects of three quite different strategic approaches to media use by candidates. 
Our task is to combine these perspectives into a model which accounts for candidate recognition and evaluation in terms of the balance of short-term forces in the campaign and the individual-level characteristics that condition voter response. In what follows, we explore the sources of name recognition and candidate evaluation as functions of personal contacts, campaign mail, and media coverage acting on individuals with different partisan identifications, readership habits, and levels of education.

\section{DATA}

This research is based upon the analysis of the responses of individual members of the electorate who were interviewed as part of the 1978 CPS National Election Study, as well as a content analysis of the campaign coverage in a sample of newspapers which they read. ${ }^{3}$ The full size of the CPS sample was 2,304 respondents. Of this total, there were 1,632 respondents who indicated that they read newspapers. Among the readers, 944 indicated that they read newspapers which were included among those which were clipped during the campaign. In general, these newspapers were the largest circulation dailies in each of the 86 congressional districts in which there was a contested race in the CPS sample of $108 .{ }^{4}$

Data are presented in Table 2 which allow comparisons of all of the respondents in the CPS sample and subgroups of nonreaders and readers on important personal characteristics and campaign related attitudes and behavior. This information, presented as mean scores for each item, in order to facilitate examination, shows that the total sample was composed of readers and nonreaders who differed in predictable ways, while, at the same time, all readers do not appear to be significantly different from the subset who read only the selected newspapers that were clipped. The items and their coding are described in detail in Appendix A.

As expected, the newspaper readers are better educated and more likely to recognize the congressional candidates than the nonreaders. With regard to their campaign involvement and electoral behavior, the readers are also more interested in the campaign and more likely to care who wins, explaining their greater likelihood to vote. Although there are no significant differences in voting behavior by party, readers are somewhat more likely to vote for incumbents than are nonreaders.

The variations in the quantity and quality of coverage of the congressional campaigns in the newspapers in the sample was substantial, as shown in Table 3. Based upon the returns from the clipping service 


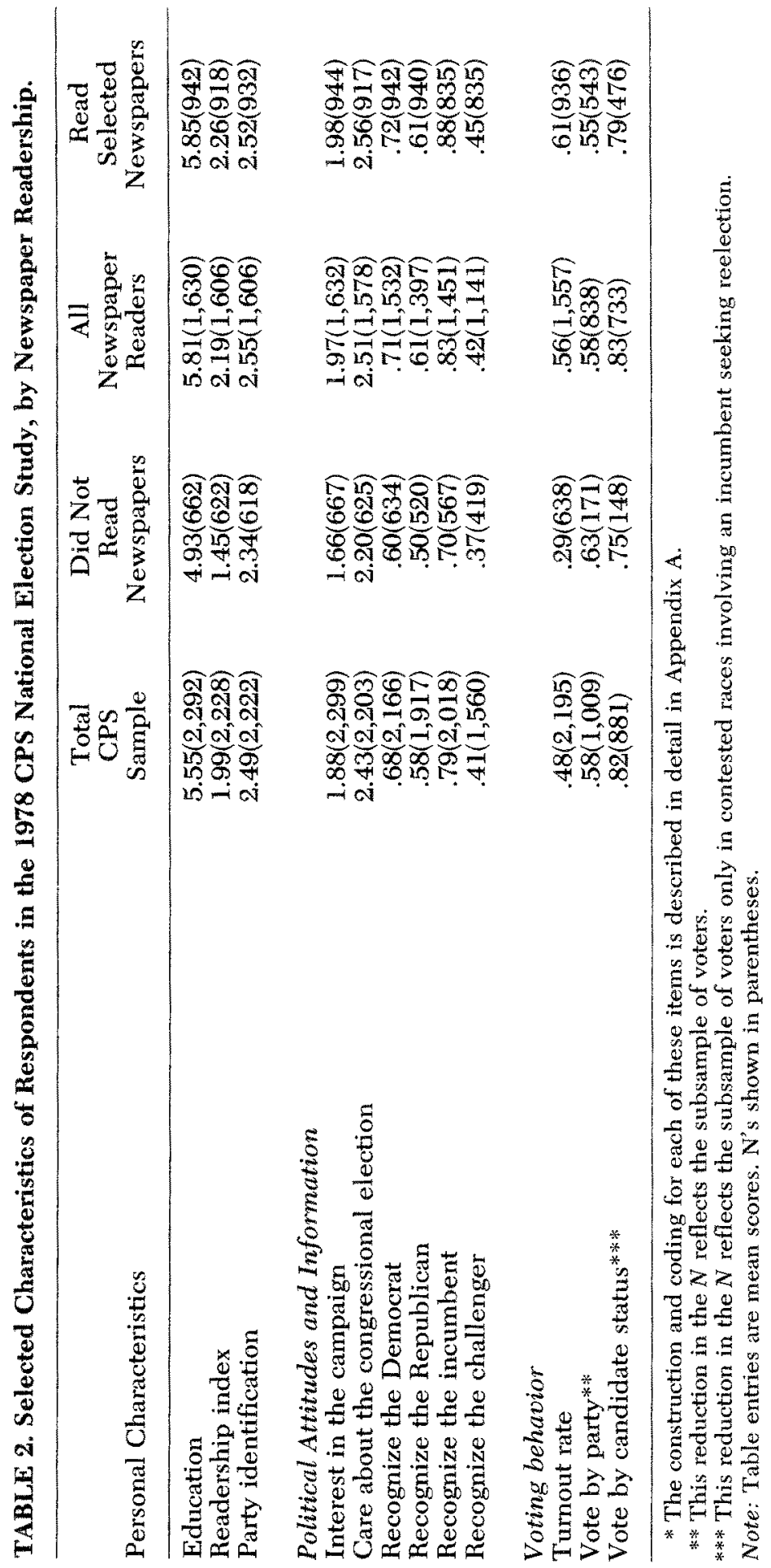




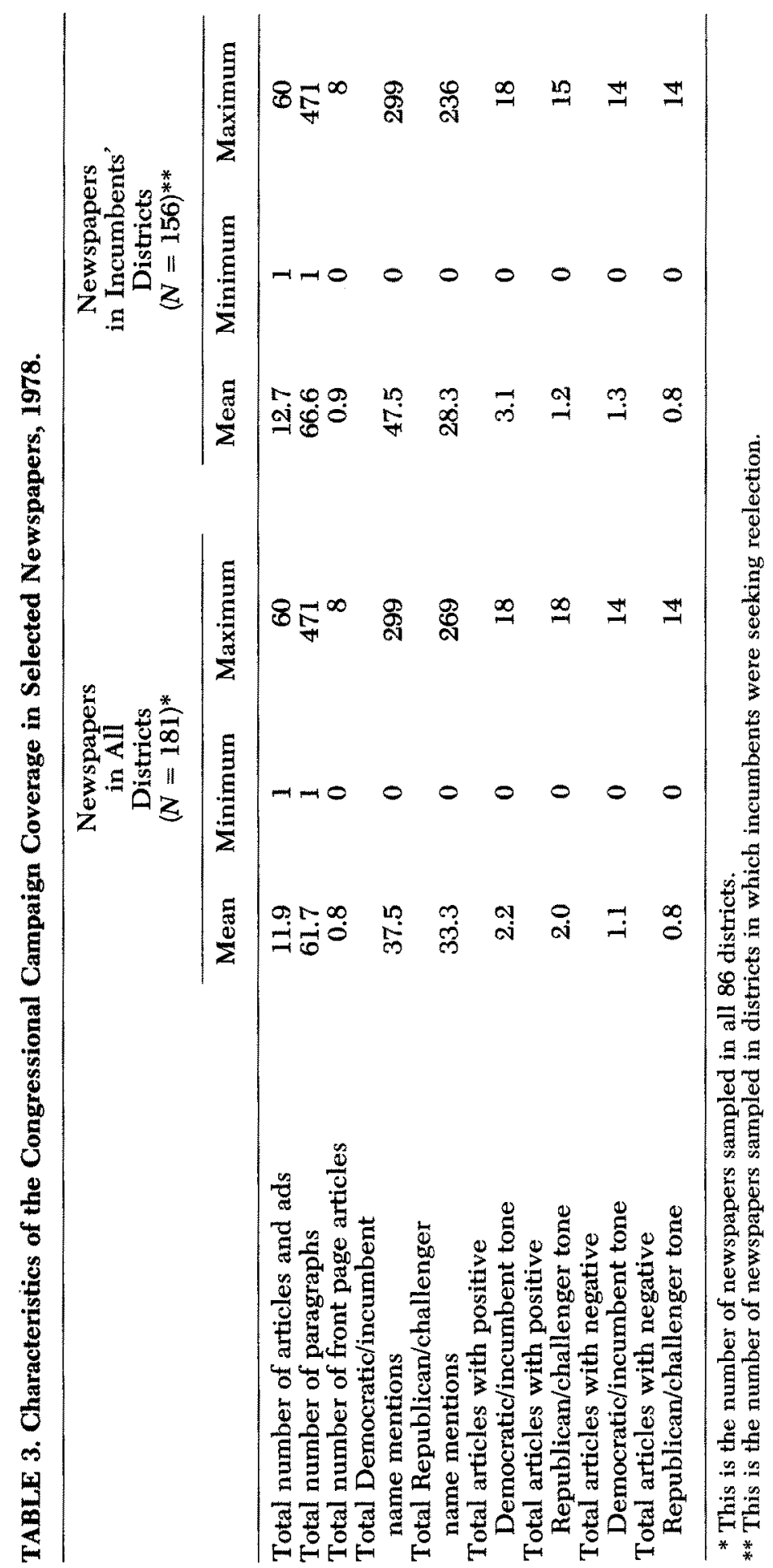


utilized by CPS, the level of campaign coverage was relatively low, averaging only 11.9 articles and ads with any mention of either candidate or the campaign more generally. However, the variation was substantial, ranging from a minimum of one article/ad to a maximum of sixty.

The data reflecting the average number of name mentions of each of the candidates in these contested races give some indication of the quality of the campaign coverage in the newspaper sample. The Democratic candidates were about 13 percent more likely, on the average, to have their names mentioned than their Republican opponents, although the range is again quite large. This advantage is clearly associated with the greater proportion of Democrats who were incumbents. When viewed as a function of candidate status, this relative advantage of incumbents is quite striking. The average rate of incumbent name mentions in the campaign coverage was 68 percent greater than for the challengers. Whereas there was only about a 10 percent difference in positive tone of the articles for Democrats relative to Republicans, incumbents were 258 percent more likely than their challengers to be described in a positive tone. Democrats and incumbents were also more likely to receive negative press coverage as well, but the number of articles was quite small.

These are the parameters of the data upon which the following analysis of campaign and media effects on voting behavior in congressional elections is based. In particular, we are interested in those factors that are associated with relative candidate recognition and evaluation, two important determinants of voter preference. The analysis will take the form of parallel presentations of data for models predicting individuals' responses to the efforts of candidates representing the two parties, and then by their relative status as incumbents or challengers. ${ }^{5}$ At first, models of recognition and evaluation of each candidate will be tested, followed by models of relative recognition and evaluation and their effects on vote preference.

RESULTS

\section{The Recognition Model}

The results of regressions predicting the recognition of Democratic and Republican congressional candidates by voters who read newspapers, including controls for their levels of education, are presented in Table 4. Recognition is operationalized as a simple dichotomous variable, and about the same proportion of the respondents could recognize each candidate, although the Democrat was more likely to be recog- 


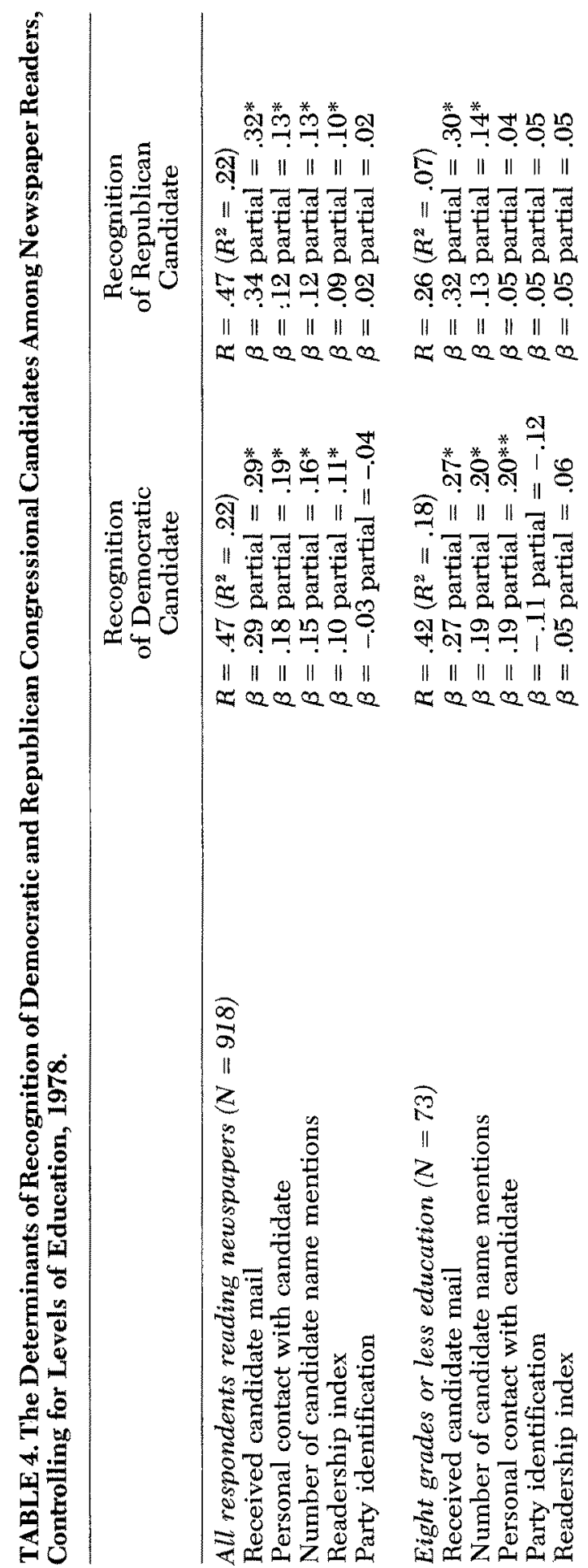


ํํำำง ำำ สิ || || || || ||

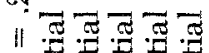

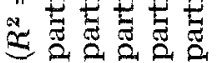

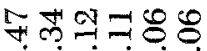
\begin{tabular}{ll|l|l|l|} 
& $\|$ & $\|$
\end{tabular} - $20 \Omega$

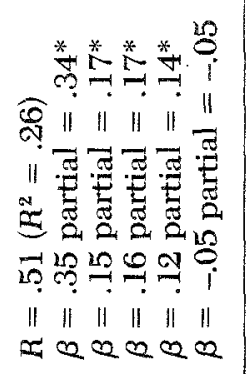

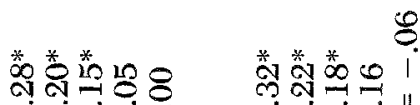
के

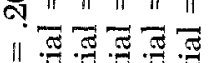
跑记

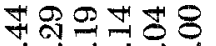
에 \|\|$\| \frac{\pi}{\pi}$ || || || || || || 100000

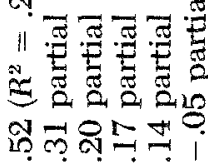
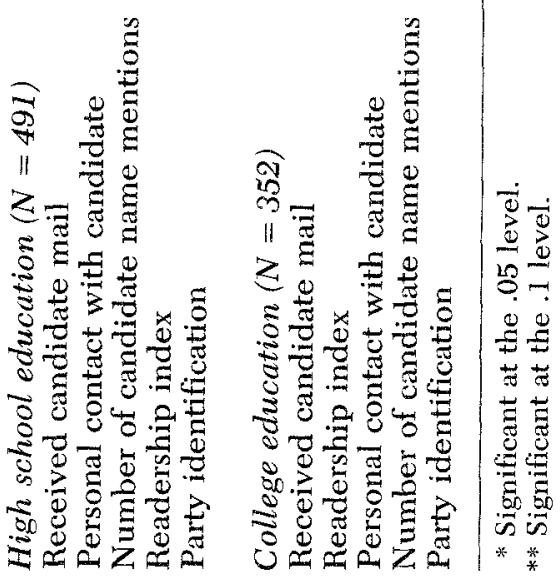
nized. Incumbents were much more likely to be recognized than challengers. The regressions explaining recognition of the candidates from either party are virtually identical. Four independent variables are significant: personal contact with the candidate, receiving mail, candidate name mentions, and newspaper readership. All these factors contribute to recognition of the candidates. Party identification has no independent influence when these important factors are first taken into consideration.

When the analysis is performed within the respondents' levels of education, the media effects are less pronounced among those with low levels of education. Their importance increases with education, as does the proportion of variance explained by the model. In the case of these and all subsequent regressions, the independent variables are listed in the order of the decreasing size of their partial correlation coefficients.

Data are presented in Table 5 for equivalent regressions testing models of the recognition of incumbents and challengers. ${ }^{6}$ For the equation that predicts recognition of the incumbent, an additional predictor indicating length of service was added. The proportion of variance explained is somewhat lower in these equations, because the variance in the dependent variable is relatively constrained due to the fact that the incumbents enjoyed such a clear recognition advantage over their challengers. Nevertheless, the general model of combined contact and media effects is confirmed in the results, illustrating the fact that media and campaign effects are important in explaining this advantage.

There are five significant predictors of recognition of the incumbent in the equation run for all newspaper readers: the two contact variables, the two media variables, and the incumbent's terms in office. Party identification remains an insignificant contributor to the explanation.

Among respondents with eight grades of education or less, of which there are a limited number among the newspaper readers, only the readership index is a significant predictor. The other media variables and the contact effects might be significant as well if the subsample size were greater. For those with a high school education, both of the contact variables and the number of name mentions in the newspaper coverage are significant. It is only among those with a college education that all five of the independent variables are significant predictors of recognition of the incumbent.

The number of candidate name mentions is more important as an independent variable predicting recognition of the challenger than the incumbent. For respondents with the lowest levels of education, receipt of mail from the challenger is the only significant predictor, 


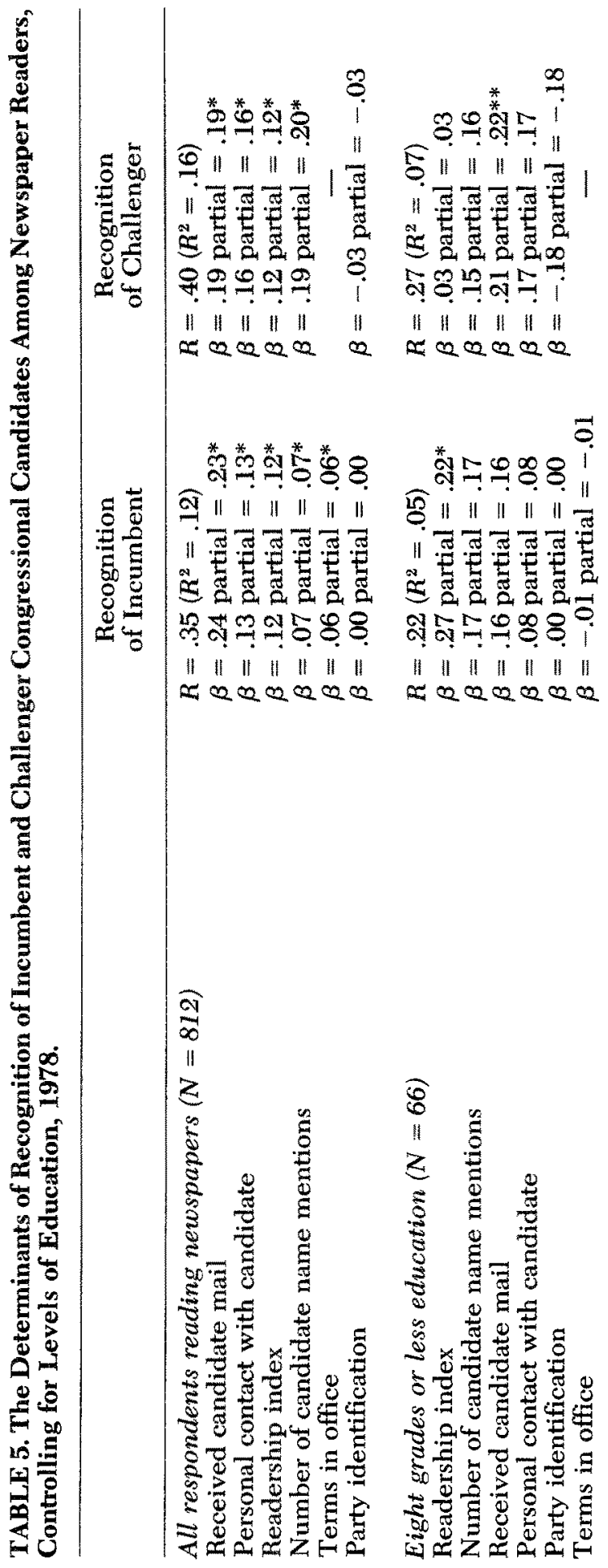




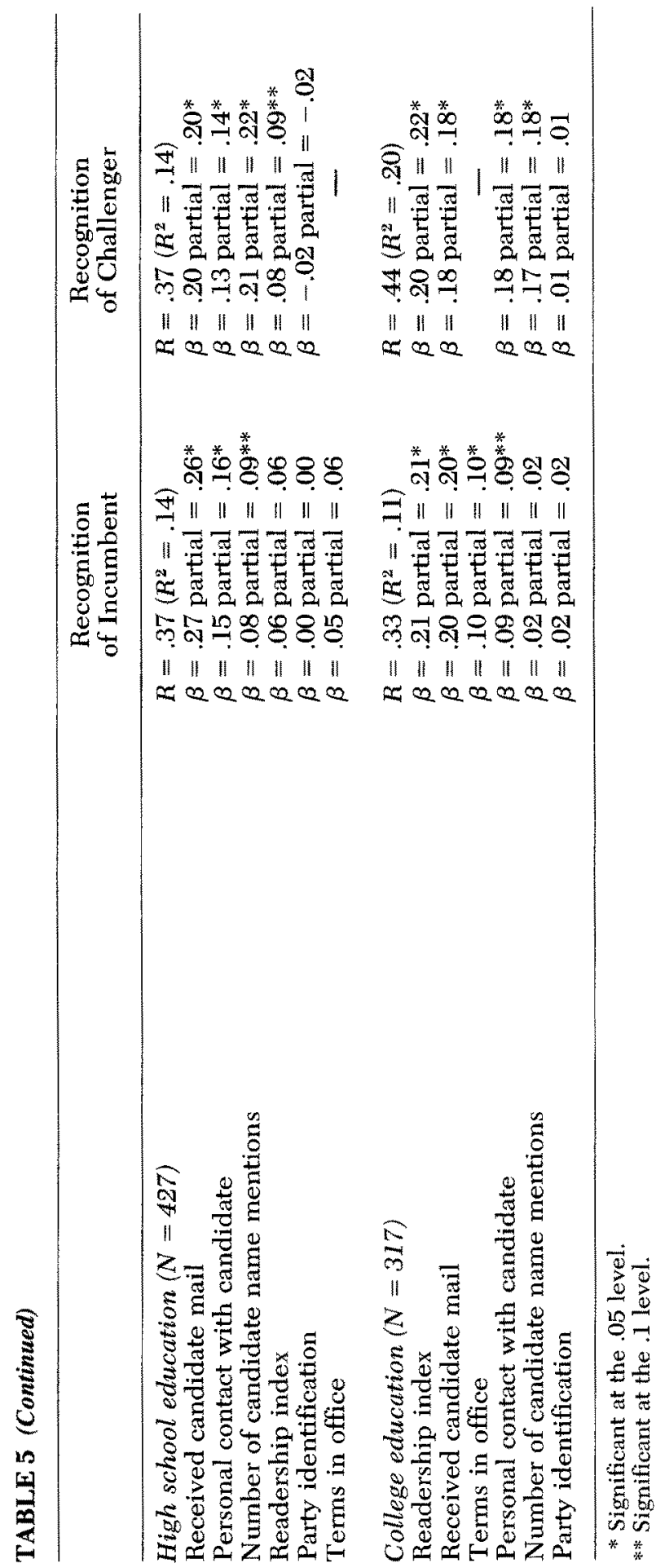


although the size of this group is small. Among those with a high school education, the most important predictor is the number of name mentions, followed by the receipt of mail from the challenger, personal contact, and the readership index. Party identification has no effect. The prediction of recognition of the challenger among collegeeducated respondents is the best equation of the six involving controls on the respondents' education $\left(R^{2}=.20\right)$, with the four main independent variables being of approximately equal importance.

The same model finds support when the independent variables are operationalized in a relative manner, as either the Democratic candidate relative to the Republican, or the incumbent relative to the challenger, in order to predict relative recognition. Relative recognition is a measure of whether the respondent can identify either or both of the congressional candidates. It is operationalized as a trichotomous variable with a value of 2 if only the Democrat (or incumbent) is recognized, 0 if only the Republican (or challenger) is recognized, and 1 if both or neither are recognized. The results of the two regressions predicting relative recognition of the candidates in accord with their party and incumbency status are presented in Table 6. Among all respondents, the relative recognition of candidates as partisans is a function of relative personal contact, relative receipt of mail, and relative number of name mentions in the newspaper. Neither readership nor party identification is significant. For relative recognition of candidates by incumbency status, these same three variables plus readership are significant, although the amount of variance explained drops.

When controls are applied by the respondents' level of education, the model predicting relative recognition for Democrats and Republicans follows the standard pattern. The amount of variance accounted for increases with education $\left(R^{2}=.22\right.$ for grade school; $R^{2}=.30$ for high school; $R^{2}=.36$ for college). Relative receipt of mail, personal contact, and name mentions are significant for the high school and college educated, but only mail remains significant in the small grade school sample.

For the model predicting relative recognition by incumbency status, less than 15 percent of the variance is accounted for in any education group. In the grade school group, receipt of mail and terms in office are significant at a lower level, whereas relative personal contact, mail, name mentions, and terms in office are all significant for the high school group. Readership replaces name mentions as a significant predictor for the college educated.

In summary, the results presented in Tables 4,5 , and 6 show that the recognition of congressional candidates is primarily a function of their 


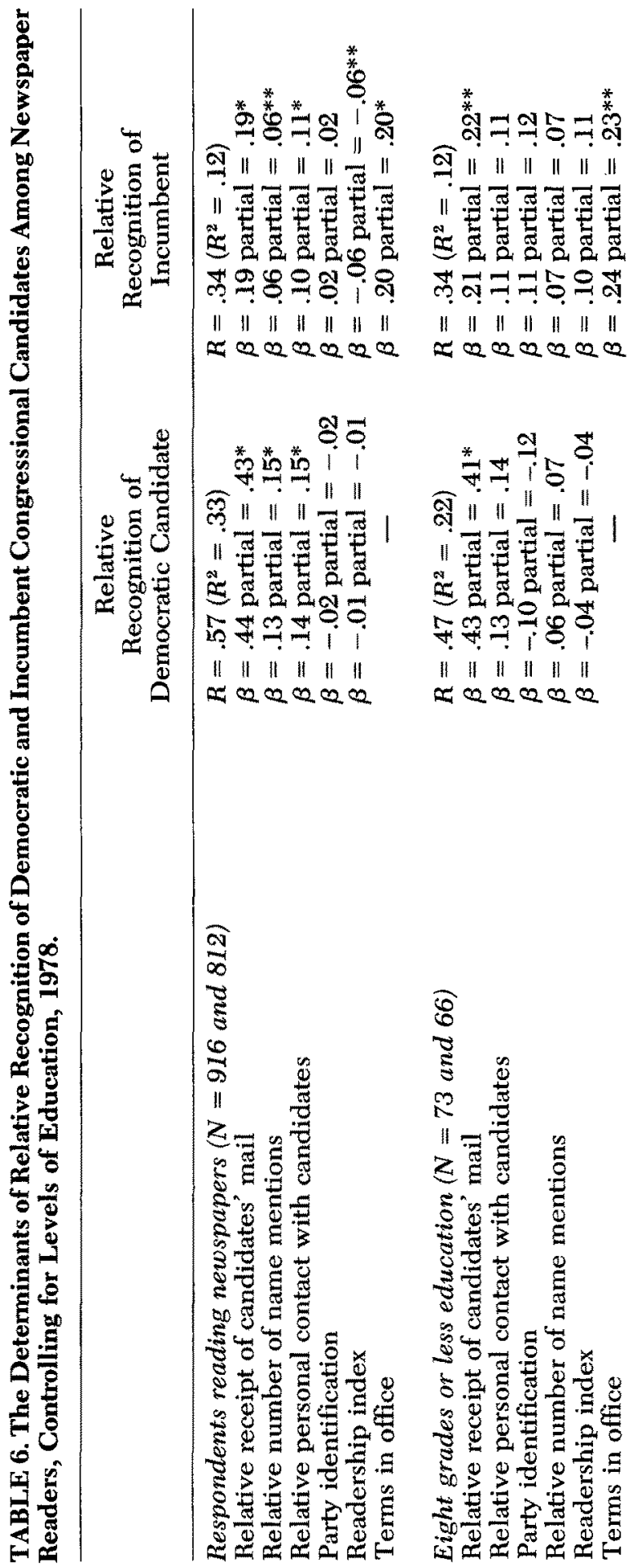



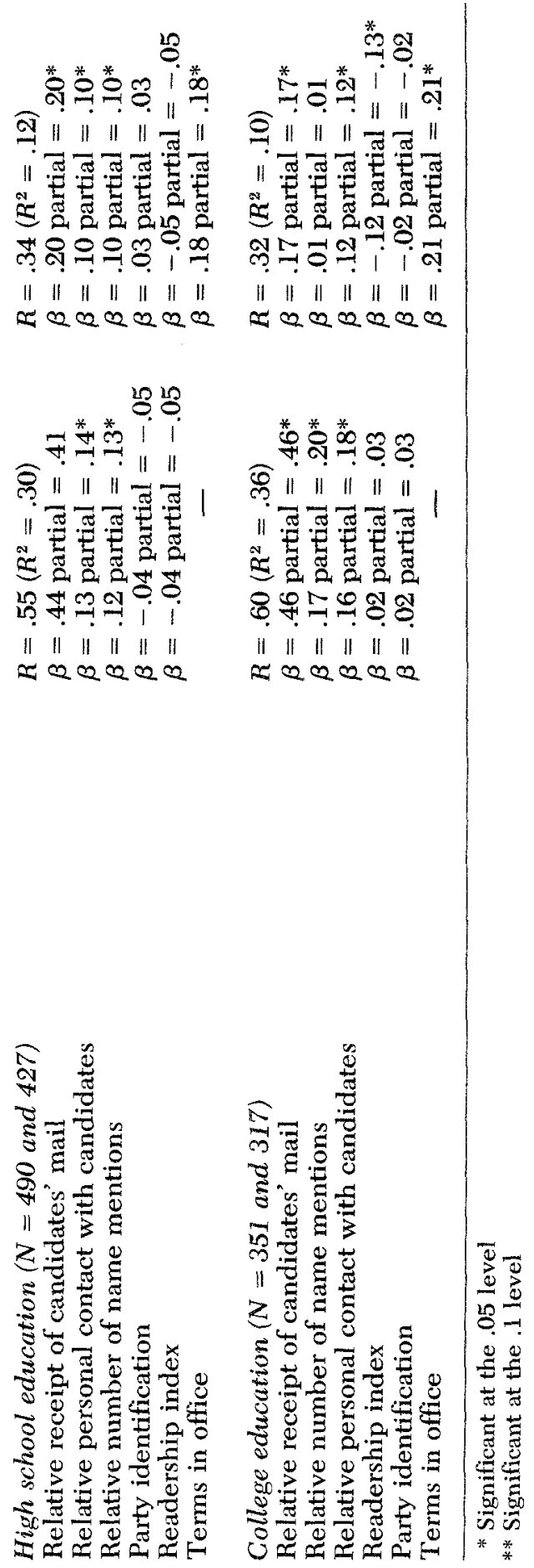
contacts and media coverage, and not of the party identification of individual voters in their district. Media coverage appears to be a more important determinant of the recognition of challengers than of incumbents, and the media variables are even better predictors of incumbent recognition than length of service. In general, the models are more successful for the better educated respondents whose amount of attention to campaign news more readily translates into recognition of candidates for office.

\section{The Evaluation Model}

When we examine the determinants of candidate evaluation, however, quite a different explanatory model emerges. Here we are explaining the ability or willingness of a respondent to assign a thermometer rating to the candidate, and a traditional model of contact effects which includes the cognitive screen of party identification works quite well. ${ }^{7}$ Neither the readership index nor the number of candidate mentions in the newspaper have any role to play in this model. A variable that measures the affective tone of the coverage was added without any effect either. The number of respondents who volunteered an evaluation of the candidates was, of course, less than the number who were able to recognize them.

Data are presented in Table 7 for the regressions on the evaluation of candidates according to their partisan affiliation. Among all of the respondents, the most important predictor is the respondent's party identification. The next best predictor is personal contact, indicating that to meet the candidates is to love them. Receipt of mail from the candidate is also a significant predictor of positive evaluation. None of the media variables are significant factors in these regression equations. Of particular interest is the noncontribution of the tone of the campaign coverage. Although much of the news reporting was clearly neutral in tone, roughly 50 percent of it could be identified as positive or negative in tone. The hypothesis that a critical press, even as a small proportion of all of the coverage, would affect the quality of the evaluations of the candidates is not supported.

Among those few respondents who were newspaper readers and had eight grades of education or less, the only significant predictor of evaluation of the Democratic candidate is receipt of his or her mail by the respondent. For evaluation of the Republican candidate, party identification is the significant predictor. Among the respondents with a high school education, the contact model appears. For evaluation of the Democratic candidate, the significant predictors are party identifi- 


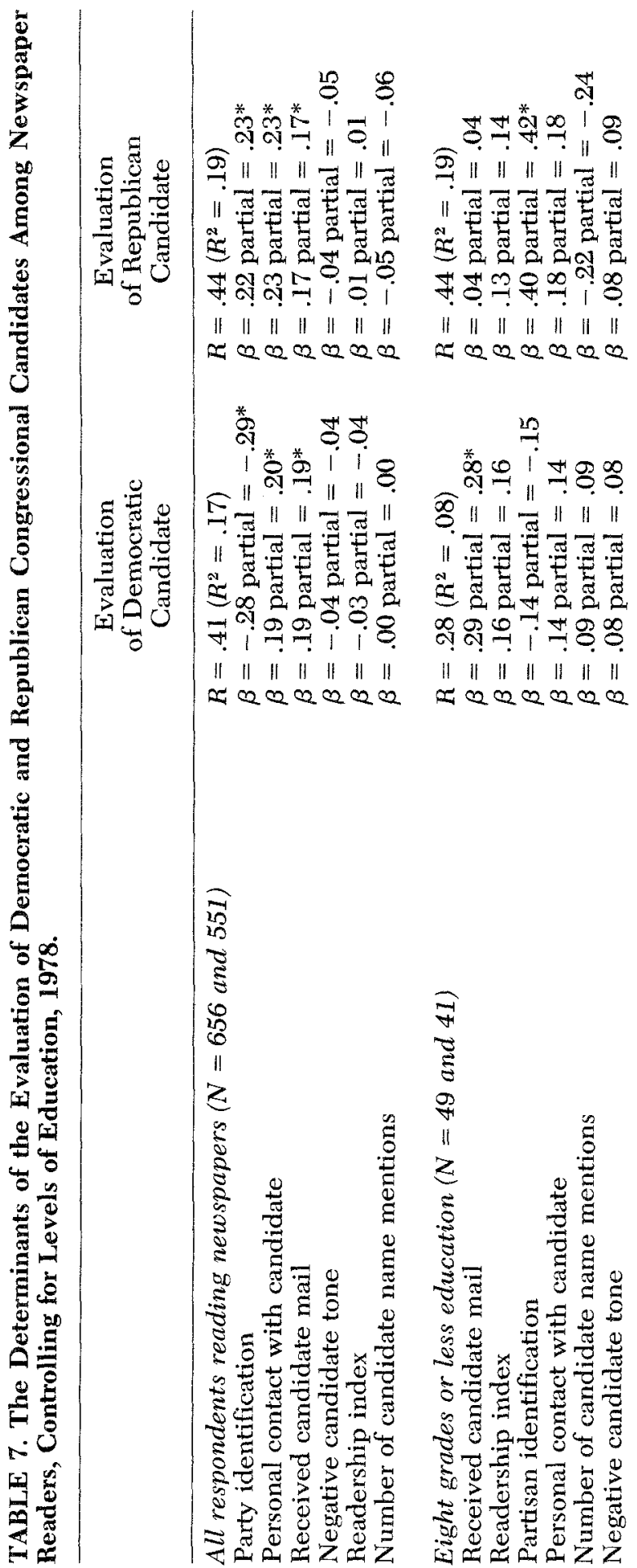




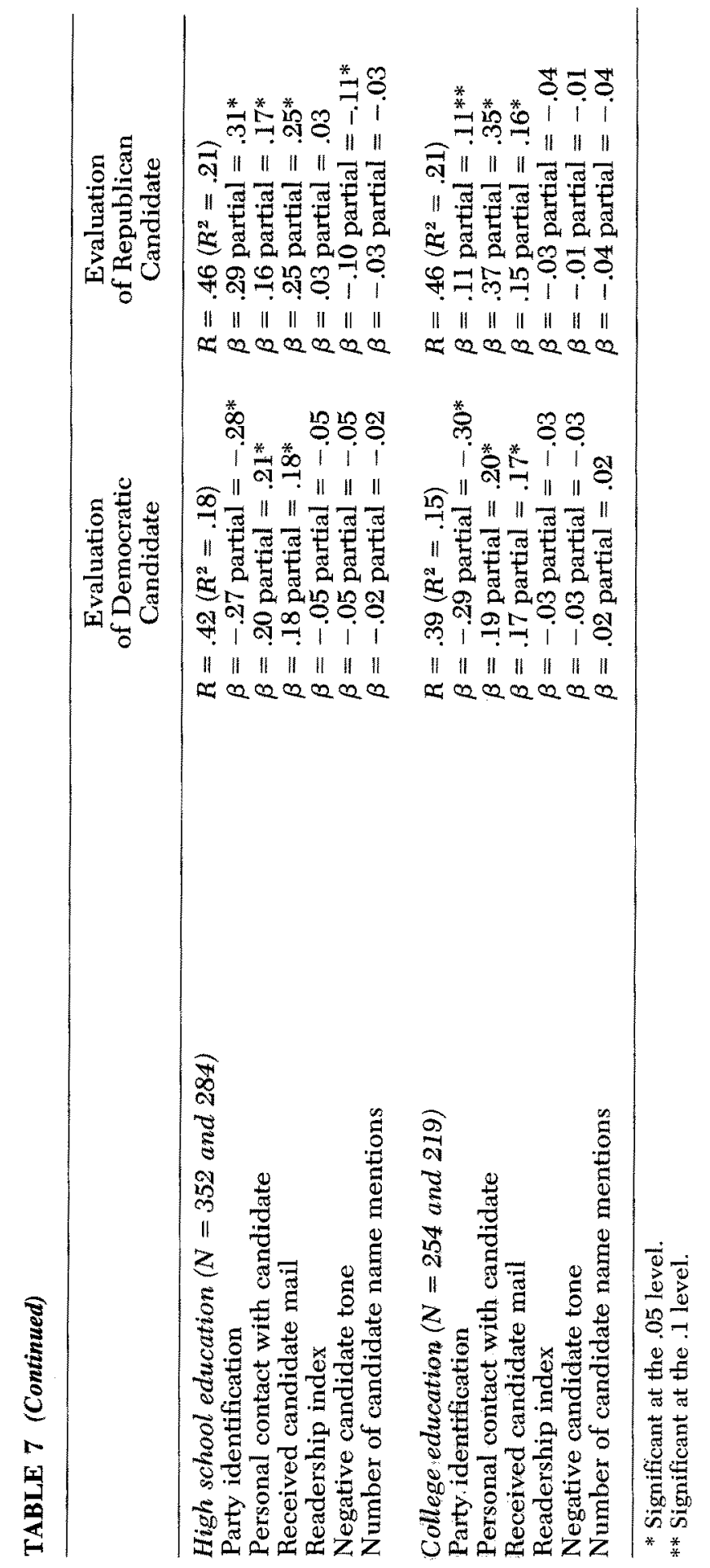


cation, personal contact, and receipt of the candidate's mail, in that order. For evaluation of the Republican candidate, the most important predictor is again party identification, and the relative importance of the other two variables is reversed. These same results are found among the college educated respondents as well.

Data presented in Table 8 relate to evaluations of incumbents and challengers, and the results are virtually identical. The most significant predictor is the party identification of the respondent, closely followed by personal contact with the candidate and receipt of mail. In the model predicting the evaluation of the incumbent, but not of the challenger, the total number of candidate name mentions is important. However, the sign is negative, contrary to what might be expected. This may demonstrate that the greater frequency of mentions is indicative of a campaign or a candidacy in trouble, similar to the finding that greater expenditures by the incumbent are associated with poorer electoral performance because they indicate a serious challenge (Jacobson, 1980).

For respondents with eight grades of education or less, evaluation of the incumbent is solely a function of party identification, while none of the independent variables are statistically significant predictors of the evaluation of the challenger. Among the respondents with a high school education, the standard model of evaluation pertains; again it is only partisanship which is significant for evaluation of the challenger. It is among the college educated that evaluation of the incumbent is adversely affected by the quality of newspaper coverage. This variable replaces receipt of candidate mail in the model. Only personal contact with the candidate and party identification are significant predictors of evaluation of the challenger.

The strength of the contact model is even clearer when these same independent variables are operationalized in a relative manner to predict relative evaluation. The results of the two regressions predicting relative evaluation of the candidates by their partisan affiliation and incumbency status are presented in Table 9 . The three-variable model of contact and party identification persists, even when the independent variables are transformed into relative measures. Among all respondents, the relative evaluation of candidates as partisans is a function of receipt of mail, personal contact, and party identification, in that order. For relative evaluation of the candidates by their incumbency status, the most important predictor is personal contact, closely followed by party identification and then receipt of mail. The equation for relative partisan evaluation explains more variance $\left(R^{2}=.38\right)$ than the one for incumbents and challengers $\left(R^{2}=.18\right)$. 


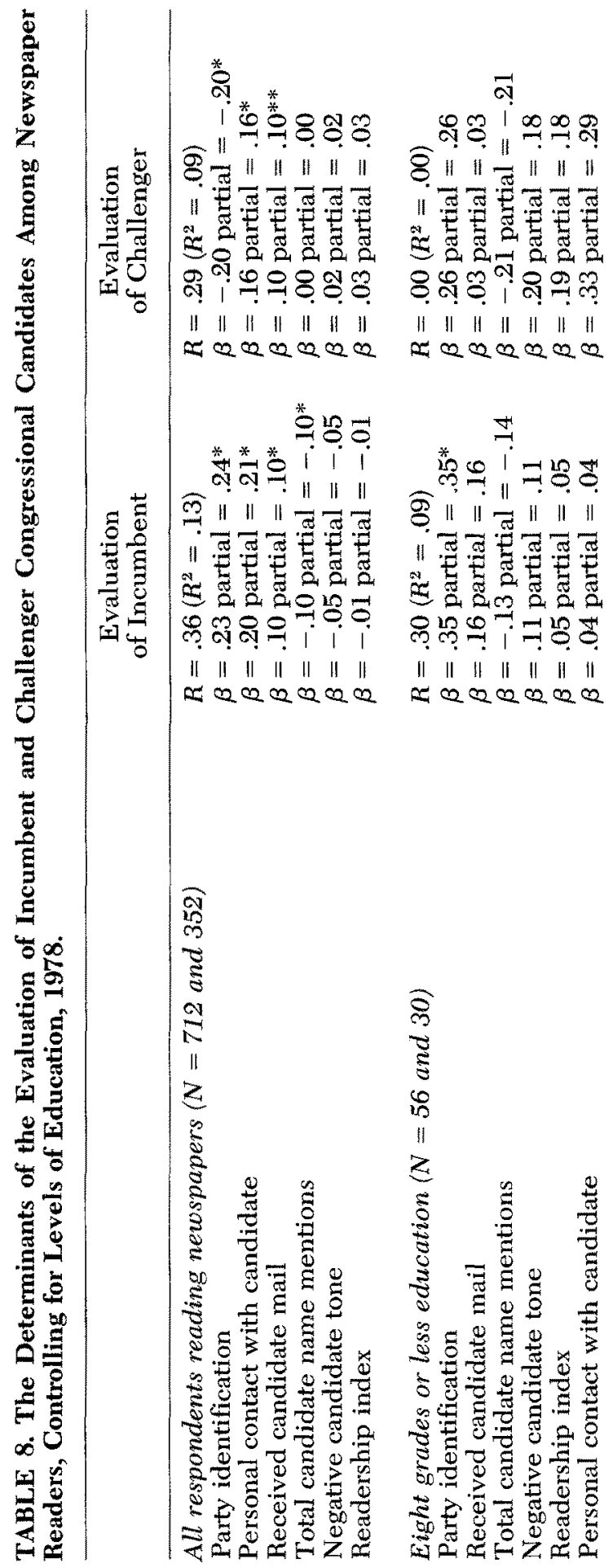



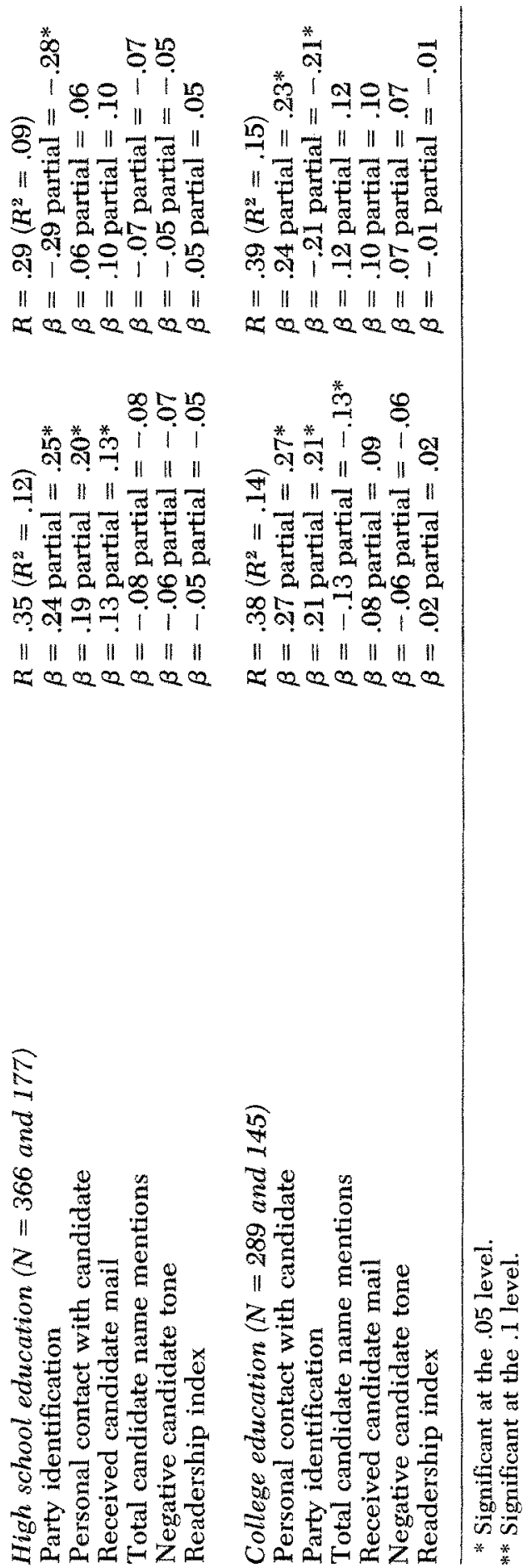


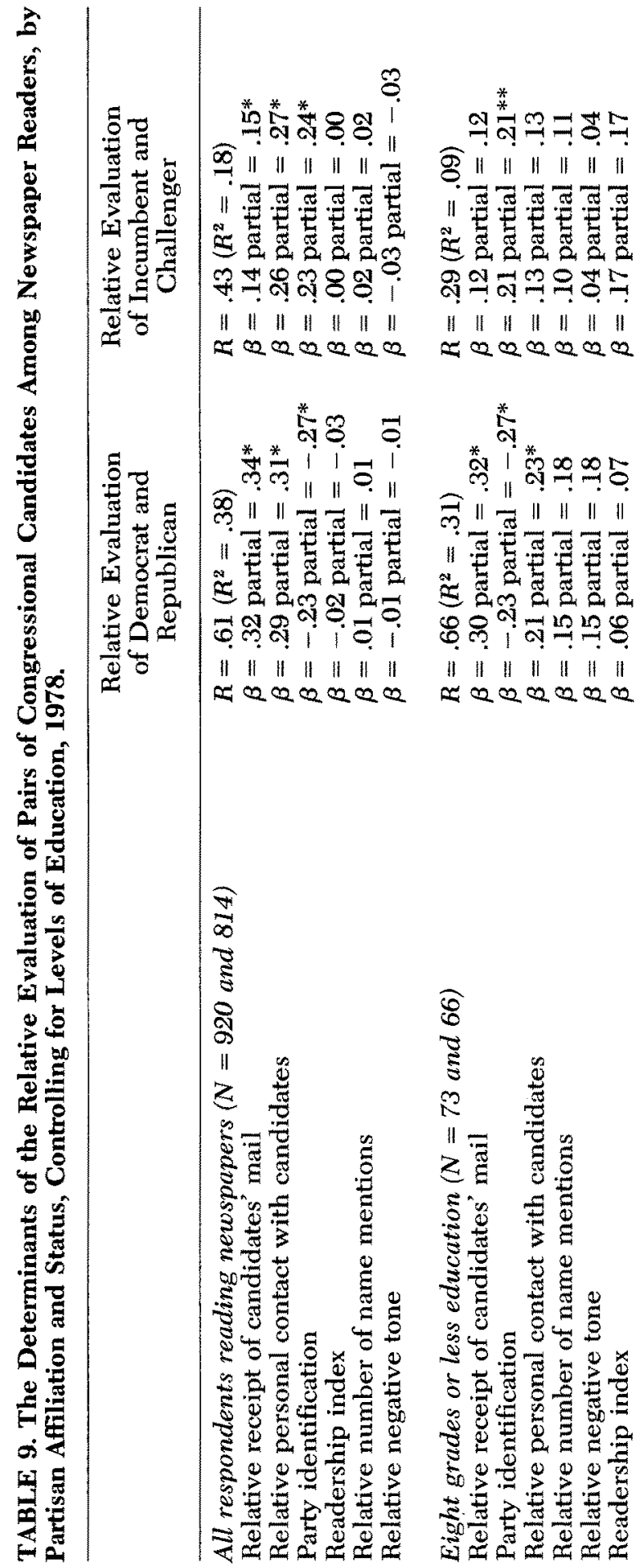



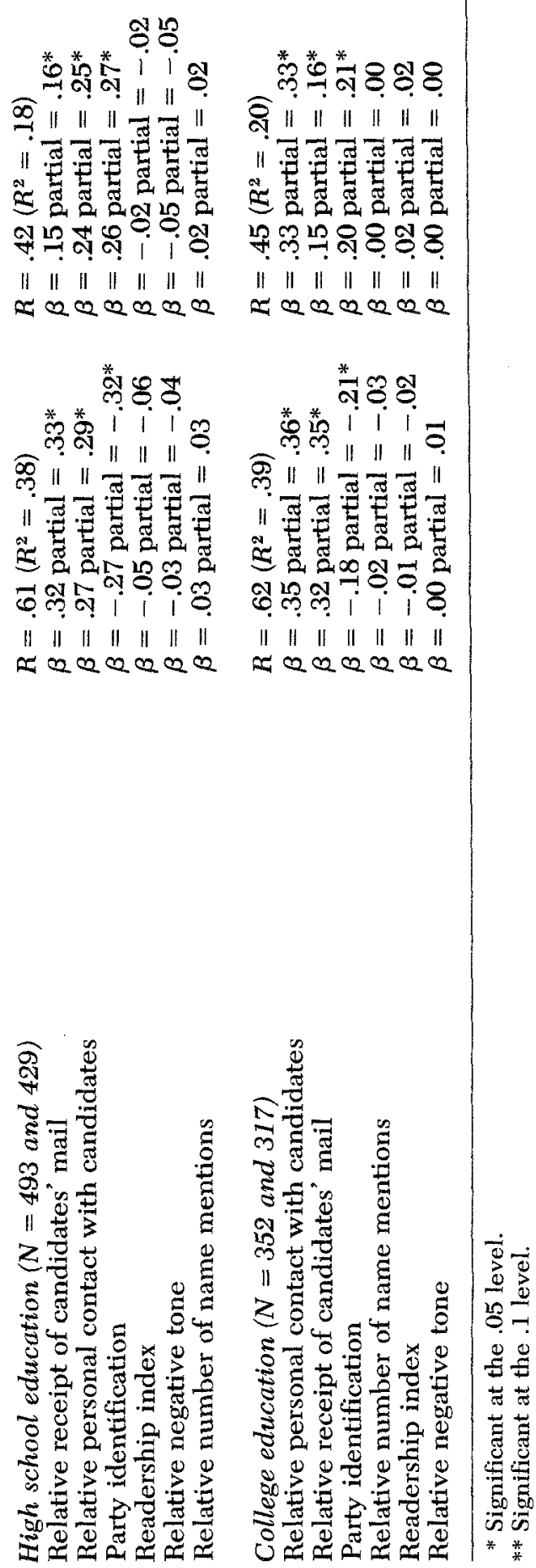
TABLE 10. The Prediction of Candidate Preference by Relative Recognition, Relative Evaluation, and Party Identification Among Voters Who Read Newspapers, 1978.

\begin{tabular}{lll}
\hline & \multicolumn{1}{c}{$\begin{array}{c}\text { Vote for } \\
\text { Democratic }(N=537)\end{array}$} & $\begin{array}{c}\text { Vote for } \\
\text { Incumbent }(N=471)\end{array}$ \\
\hline & $R=.77\left(R^{2}=.60\right)$ & $R=.66\left(R^{2}=.44\right)$ \\
Relative evaluation & $\beta=.49$ partial $=.53$ & $\beta=.45$ partial $=.49^{*}$ \\
Party identification & $\beta=-.28$ partial $=-.38$ & $\beta=.31$ partial $=.37^{*}$ \\
Relative recognition & $\beta=.22$ partial $=.29$ & $\beta=.13$ partial $=.17^{*}$ \\
\hline
\end{tabular}

* Significant at the .01 level.

These same relationships appear consistently when controls are applied by the respondents' level of education. Party identification, significant in all six equations, is more important in explaining the relatively better evaluations of incumbents compared to challengers, rather than of Democrats compared to Republicans. None of the media variables-including relative number of name mentions and relative negative tone in the coverage-is significant in any of the equations.

\section{The Combined Effects Model}

It remains to demonstrate the importance of relative evaluation and relative recognition for voting behavior in congressional elections. Data are presented in Table 10 for the prediction of candidate preference among voters who read newspapers in the 1978 CPS American National Election Study. In the equation predicting the vote for the Democratic candidate $\left(R^{2}=.60\right)$, the most important independent variable is relative evaluation, although party identification and relative recognition are also highly significant. ${ }^{8}$ An altemative equation that added a term for incumbency status resulted in the explanation of only 1 percent more of the variance, demonstrating that these concepts effectively capture the essence of the incumbents' advantage and leave little independent effect of the candidate's status. For prediction of a vote for the incumbent, these three variables are again highly significant, although relative recognition makes somewhat less of a contribution here than to the first equation.

\section{CONCLUSIONS}

Two quite distinct but complementary models of the determinants of candidate recognition and evaluation have been developed. The rec- 
ognition model combines contact and media effects, and there is no direct role for party identification. Evaluation is a relatively straightforward function of contact effects in which personal contact is very important, and party identification is significant as well. The media variables reflecting the quantity and quality of coverage are insignificant.

To return to our original premise, vote choice is a function of campaign factors working on individuals with varying predispositions, but the pattern is not a simple one. Campaign activities, such as rallies and coffee klatches, mass mailings and ads, or news events, all contribute to the likelihood that someone will recognize a candidate, especially if that someone attends to considerable campaign news. This is more true of the highly educated than the less-well-educated voters. Incumbents enjoy an added advantage if they have served in office for a while. And, in general, news coverage is more important for challengers than for incumbents.

With regard to candidate evaluation, party identification is an important screen that is penetrable by mass mailings and personal encounters, but not by media content-at least not at the levels of coverage experienced in congressional races. These techniques are less potent in affecting vote choice between incumbent and challenger. There is no evidence that the education level of an individual voter is an important conditioner. Either education is an inadequate operationalization of the concept of mass of stored information about politics, or less mass does not produce more vulnerability to media appeals.

Finally, treating the contested campaign as a two-person contest, building measures which capture how one candidate fares relative to the other, is a sensible and workable analytical approach. Relative recognition, relative evaluation, and party identification are three important contributors to candidate preference, and incumbency adds very little explanatory power beyond what is already contained in incumbent recognition and evaluation advantages. The models presented and tested here constitute a first step toward providing substantive content to the campaign aspects of incumbency advantage in races for the U.S. House of Representatives.

\section{APPENDIX A}

The mean scores presented in Table 2 are based on the scoring of relevant variables as follows: 
Education of the Respondent

1. 8 grades or less

2. 8 grades or less plus nonacademic training

3. 9-11 grades

4. 9-11 grades plus nonacademic training

5. High school diploma

6. High school diploma plus nonacademic training

7. Some college, but no degree

8. Junior/community college degree

9. BA level degree

10. Advanced degree

\section{Party Identification}

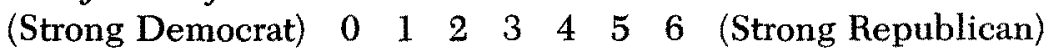

Recognize the Candidate (Could volunteer a thermometer rating for a given name or recall the candidate's name independently). Each candidate can be categorized as a Democrat or a Republican and in appropriate districts, as an incumbent or a challenger.

0 . Does not recognize candidate

1. Does recognize candidate

\section{Turnout Rate}

0 . Did not vote

1. Voted

Vote by Party

0 . Voted for Republican candidate

1. Voted for Democratic candidate

Vote by Candidate Status (where relevant)

0 . Voted for challenger

1. Voted for incumbent

Readership Index. Did you read about the campaign in any newspaper? How many articles did you read about the campaign for the U.S. House of Representatives in your district?

1. No newspaper articles read about campaign

2. Only one or two articles read

3. Several or a good many articles read

Interest in the Campaign. Some people don't pay much attention to campaigns. How about you? Would you say you were very much interested, somewhat interested or not much interested in following the political campaigns this year?

1. Not much interested 


\section{Somewhat interested \\ 3. Very much interested}

Care about the Congressional Election. How much would you say you personally cared about the way the elections for the U.S. House of Representatives came out?
1. Not at all
2. Not very much
3. Pretty much
4. Very much

\section{NOTES}

1. All four of the measures of media exposure used to construct the index were not asked in the off-year CPS studies until 1978. As a result, the index of general campaign exposure in presidential years must be used to control for the relationship between party identification and party voting for U.S. Representative in these years. The 1978 data are based upon exposure measures related directly to the congressional campaigns.

2. The intercorrelation (Pearson's $r$ ) for the Media Exposure Index and Newspaper Readership is .57 .

3. Other media sources are available and will be content analyzed for subsequent use, including coverage in weekly newspapers, campaign literature, and limited numbers of radio and television spot announcements.

4. The selection criteria for newspapers included any within the district that circulated to more than $25 \%$ of the households in a county within a district or a sub-county district; any paper from outside the district that circulated to more than $50 \%$ of the households within a county in a district or a sub-county district; and any paper with a circulation of 50,000 or more within the district. The use of the clipping service was part of the original CPS data collection effort; the authors were responsible for content analysis of a selected subsample of the clippings.

5. The analyses presented in this paper are the results of using multiple regression models. Some analysis was performed utilizing a logistic form of dichotomous regression, and the results were identical. Two of the four dependent variables in this study are measured at the interval level; in the interest of simplicity of presentation, only the results of one technique are given consistently here.

6. In the paired presentations of data by partisan affiliation and then by status of the candidates, there will be an associated reduction in the sample size in the latter case due to the elimination of respondents residing in districts where no incumbent was running (open races).

7. A feeling thermometer is a data collection device whereby respondents are asked to assign a score to their feelings toward a candidate in terms of a scale ranging from extreme coolness ( 0 degrees) to extreme warmth (100 degrees), with 50 degrees indicating neutrality. The relative evaluation measures are the difference between the ratings of pairs of candidates who are the Democrat and Republican and the incumbent and challenger.

8. These results are virtually identical to regressions run for all voters in the CPS sample, without consideration of newspaper readership habits.

\section{ACKNOWLEDGMENTS}

Portions of the data collection and analysis presented here were supported by Grant 
No. SOC 78-18710 from the National Science Foundation. The 1978 CPS American National Election Study data were collected under a grant from the National Science Foundation and supplied by the Inter-university Consortium for Political and Social Research. Neither the ICPSR nor NSF bears any responsibility for the analyses presented here.

The research assistance of Charles H. Franklin III is gratefully acknowledged.

\section{REFERENCES}

Abramowitz, Alan I. (1975). "Name Familiarity, Reputation, and the Incumbency Effect in a Congressional Election." Western Political Quarterly 27: 668-684.

(1980). "Party and Individual Accountability in the 1978 Congressional Election." Paper presented at the Rice-Houston Conference on Congressional Elections, January 10-12.

Campbell, et al. (1960). The American Voter. New York: Wiley.

Converse, Philip E. (1966), "Information Flow and the Stability of Partisan Attitudes." In Angus Campbell et al. (eds.), Elections and the Political Order. New York: Wiley, 136-158.

Dreyer, Edward C. (1971-2). "'Media Use and Electoral Choices: Some Political Consequences of Information Exposure." Public Opinion Quarterly 35: 544-553.

Goldenberg, Edie N., and Michael W. Traugott (1980). “Campaign Effects on Outcome in the 1978 Congressional Elections." Paper presented at the Rice-Houston Conference on Congressional Elections, January 10-12.

(1979). "Resource Allocations and Broadcast Expenditures in Congressional Campaigns." Paper presented at the 1979 Annual Meeting of the American Political Science Association Meeting, Washington, D.C., August 31-September 3.

Jacobson, Gary C. (1980). "Congressional Elections, 1978: The Case of the Vanishing Challengers." Paper presented at the Rice-Houston Conference on Congressional Elections, January 10-12.

Mann, Thomas, and Raymond Wolfinger (1979). "Candidates and Parties in Congressional Elections." Paper presented at the 1979 Annual Meeting of the American Political Science Association, Washington, D.C., August 31September 3.

Mann, Thomas (1978). Unsafe at any Margin: Interpreting Congressional Elections. Washington: American Enterprise Institute.

Mayhew, David (1974). "Congressional Elections: The Case of the Vanishing Marginals.” Polity 6: 295-317.

Parker, Glenn (1980). "Incumbent Popularity and Electoral Success." Paper presented at the Rice-Houston Conference on Congressional Elections, January 10-12.

Robinson, John P. (1974). "The Press as King-Maker: What Surveys from the Last Five Campaigns Show." Journalism Quarterly Winter, pp. 587-594. 